\title{
2nd SETAC Europe Young Environmental Scientists (YES) Meeting 2011 at RWTH Aachen University, 28 February till 2 March 2011
}

\author{
Environmental challenges in a changing world
}

\author{
Mirco Bundschuh · Jochen P. Zubrod • Nika Galic • André Dabrunz - Michael Melato • Claudia Mieiro • \\ Stephanie Sdepanian • Ola Westman · Tao Liu • Dominic Kaiser • Markus Brinkmann
}

Received: 29 June 2010/Accepted: 30 June 2010/Published online: 23 July 2010

(C) Springer-Verlag 2010
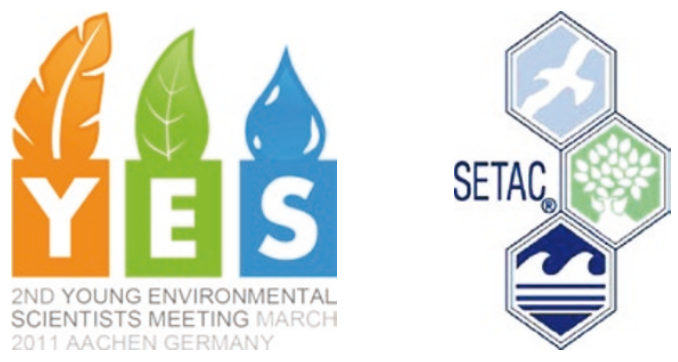

\section{Introduction}

Since 2006, the SETAC Europe Student Advisory Council (SAC) has represented student members (master, diploma or Ph.D. students) throughout every level of SETAC and provides additional advice, recommendations and new

M. Bundschuh $\cdot$ J.P. Zubrod · A. Dabrunz

Institute for Environmental Sciences,

University Koblenz-Landau,

Campus Landau, Im Fort 7, 76829 Landau/Pfalz, Germany

N. Galic

Wageningen University and Alterra,

P. O. Box 47, 6700AA Wageningen, The Netherlands

M. Melato

Faculty of Applied Science,

Cape Peninsula University of Technology,

P.O. Box 652, Cape Town, 8000, South Africa

C. Mieiro

CESAM and Department of Chemistry,

University of Aveiro,

Campus de Santiago, 3810-193 Aveiro, Portugal

S. Sdepanian

Lancaster Environment Centre,

Lancaster University, Bailrigg,

Lancaster, LA1 4YQ, United Kingdom initiatives to the SETAC Europe Council. One of these new initiatives was the organization of the first Young Environmental Scientists (YES) Meeting in March 2009 at the University of Koblenz-Landau, Germany. The meeting was a great success (Bundschuh et al. 2009) and after much effort by the SAC we are finally able to announce the 2nd YES-Meeting to be held on 28 February till 2 March 2011 at RWTH Aachen University, Germany, the home institution of the acting chair of the SAC, Markus Brinkmann. The local organization of the meeting will be carried out by students of Environmental Science from Aachen University, which excels in its competence regarding environmental toxicology and chemistry and has been awarded funding for all three funding lines within the Excellence Initiative of the German Federal and State Governments.

O. Westman

Man-Technology-Environment Research Centre,

School of Science and Technology, Örebro University,

70182 Örebro, Sweden

T. Liu

School of Pure and Applied Natural Sciences,

Linnaeus University,

39182, Kalmar, Sweden

D. Kaiser

Institute for Ecology, Evolution and Diversity,

Goethe-University Frankfurt,

Siesmayerstrasse 70, 60323 Frankfurt, Germany

M. Brinkmann $(\square)$

Department of Ecosystem Analysis,

Institute for Environmental Research,

RTWH Aachen University,

Worringerweg 1, 52074 Aachen, Germany

e-mail: markus.brinkmann@bio5.rwth-aachen.de 


\section{How to prepare excellent scientific publications and presentations}

The upcoming YES-Meeting is again organized as a studentonly conference aiming to fulfil the special needs of young scientists working in the field of environmental chemistry, ecotoxicology and life cycle assessment. The meeting will start with a workshop on "how to prepare excellent scientific publications and presentations" held by Dr. Peter Chapman (Golder Associates, Canada) with the aim of helping students overcome typical problems they encounter when first trying to communicate research results to the scientific community. Additionally, this workshop will prepare students for the submission of high-quality papers to scientific journals.

\section{Scientific program}

Following on from the Workshop the scientific program entitled "Environmental challenges in a changing world" will discuss environmental issues at the cutting edge of science. Topics will include those that are intensively discussed within the scientific community, i.e.,

- nanomaterials,

- omics and biomarkers,

- remediation techniques,

- risk assessment,

- modelling

as well as more general topics such as

- environmental chemistry,

- aquatic and terrestrial ecotoxicology

but also

- life cycle assessment.

After every $15 \mathrm{~min}$ platform presentation a considerable time will be given for a discussion of the presented results and for suggestions concerning style and performance of the presentations.

\section{Career talks}

The scientific program is accompanied by so-called "Career talks". The aim of this session is to provide students with a clear understanding of how to make future plans in consideration of the tripartite structure of SETAC:

- Prof. Dr. Juliane Hollender from EAWAG (Switzerland) will represent academia,

- Dr. Annemarie van Wetzel from the National Institute of Public Health and the Environment in the Nether- lands will provide deeper insight into regulatory work, and

- Dr. Steve Maund from Syngenta (Switzerland) will present his experiences in industry.

\section{Job corner}

Another major part of the meeting will be the "job corner", which will provide an excellent opportunity for young scientists to make initial contact with possible future employers. On the other hand, employers will have a perfect opportunity to introduce themselves to the "new blood" of the environmental science community as a first step in their prospective manpower planning.

\section{Closing remarks}

Financial support from various sources has enabled the conference organizers to run the meeting without the need to charge a conference fee and to provide a travel grant for each invited participant who gives a platform or poster presentation. Selection for any kind of presentation will solely be based on the scientific quality of the abstracts submitted until 31 October 2010 via the meeting homepage (http://yes2011. sac-online.eu). Furthermore, the local organizing committee will provide cheap accommodation for participants, as these expenses are not covered by the meeting budget.

\section{Sponsors}

This meeting is financially supported by SETAC Europe, SETAC GLB, RWTH Aachen University, the German Chemical Industry Association, the Wageningen Institute for Environment and Climate Research (WIMEK), Dr. Knoell Consult, Bayer, Syngenta, and Hydrotox.

Please visit the meeting webpage for further information at http://yes2011.sac-online.eu or send an email to yes@ sac-online.eu.

\section{References}

Bundschuh M, Dabrunz A, Bollmohr S, Brinkmann M, Caduff M, Gomez-Eyles JL, Kienle C, Melato M, Patrick-Iwuanyanwu KC, Van Hoecke K, Seiler T-B, Brooks A (2009) 1st Young Environmental Scientists (YES) Meeting - New challenges in environmental sciences. Environ Sci Pollut Res 16(4):479-481 